\title{
Strategy Analysis of Real Estate Network Marketing
}

\author{
Zhang Qiang \\ School of Economic and Management \\ Shengyang Aerospace University \\ Shengyang, China \\ Zhangqiang@sau.edu.cn
}

\begin{abstract}
China's real estate industry has made a great success and created great fortunes. However the close ratio has stagnated and even declined along with government's control policies and people's rational concepts toward housing demand. Under the circumstance of unfavorable policy and market, precise marketing methods should be adopted to promote development project and sales. What's more, with the development of network in China, its marketing influence has been enhanced. And traditional marketing sales cannot attract young consumers who rarely reach out to traditional media. So network marketing is in trend and will definitely become main marketing tactics for all industries.

Keywords-real estate; network marketing; real estate network marketing; forum marketing; wechat marketing;
\end{abstract}

\section{INTRODUCTION}

With the development of times and technological progress, people ask higher and higher requirement about accommodation. As a result, the competition among real estate becomes fierce and mature. All real estate developers should get a clear understanding of the current situation to develop productive force with science and innovation based on advanced science and technology. Only by this, can it satisfy the needs of social development, meet legal requirement and at the same time achieve the maximum of social and economic benefits. What's more network marketing has become one of the most important ways among various marketing planning in the real estate circle.

II. OVERVIEW OF REAL ESTATE NETWORK MARKETING

Real estate network marketing refers to a mode of business operation to sale products and services during the process of developing, running, sales and management with network technology to achieve real estate values.

Because of its special features, the role of network marketing has played in real estate industry still remains in the initial stage of buying behavior. What's more, its function in identifying purchasing behavior and transaction is not comprehensive with huge differences in the role real estate marketing has played in different real estate enterprises.

\section{CURRENT SITUATION OF REAL ESTATE MARKETING}
A. Network is in the trend for future social development

The sales volume of Tmall and Taobao (China's ebusiness platforms) in 11th November 2013 (which has sales promotion) has reached to RMB 30 billion Yuan, which is twice as much as sales of three quarters of Wangfujing department store; sales of half the year of Wal-Mart supermarkets in China; 4.5 times of 110 Beijing key enterprise sales during the golden week of the National Day; 40 times of sales of 9 Guangzhou department stores; and more than 100 times of sales of 9 Chengdu department stores.

B. Real estate industry which was adapted to the development of times is now overturned by network

Fenglun established Zhuchao network in 2000, and he intended to carry out positive interaction with customers. He has set up the whole process of purchasing, such as placing an order, transaction, etc. It means that Fenglun provides land for housing, and people who have purchase intention determine the dwelling size, material and purpose. What's more, JILIN WANTONG PHARMACY GROUP CO. is responsible for specific operation after a process of communicating.

Recently, information is released that Xiaomi Company is going to build apartments for staffs, which means it plans to go into the real estate industry, and this industry may be overturned by network. Fenglun is astonished by this information, yet he is not affected. What's more, he has said assertively in Yabuli forum that he won't stand still, and is going to embrace the challenge of internet enterprises with enthusiasm.

\section{Nowadays real estate network promotion is restricted to promotion}

Almost all the participants in network promotion regard this method as network marketing, which is a wrong recognition. The combination of real estate and network is not network marketing now but still remains in the stage of network research and promotion. Marketing can be broadly divided into research, positioning, package promotion, sales, etc. However, the existing network marketing cannot afford these, which only include research and package promotion. 


\section{StRategy ANALysis OF REAL Estate} NETWORK MARKETING

A. Real estate network promotion through professional website

1) Display advertising

This promotion is a fairly common way in the internet with brief information attempting to sale real estates.

Advantages: It occupies a small space with low advertising cost. What's more, this advertising is set in the primary or middle position, which will definitely leave an impression in customers' heart though without detailed contents.

Disadvantages: A large amount of display advertising is crowded in a small space, which will confuse customers. In addition, the advertising will rarely be focused without distinct advantages. What's more, because of its small space, just the project name and telephone information of sales offices are included (part of the advertising can demonstrate preferential prices with the range of sales area, yet they can rarely attract attention with single words). Furthermore, detailed information cannot be displayed, which will lose potential customers and cause interest loss.

2) Floating services

Floating services appear both in real estate network promotion but also in game advertising. This kind of advertising will always come into your eye no matter you drop down web pages or not, which is actually fatal mind blast to customers or potential customers.

Advantages: It is difficult to forget this kind of advertising because of its mobility, which will leave a deep impression for customers.

Disadvantages: It will cause irritable and negative emotions because of its mobility. What's more, it cannot demonstrate all the information because of the small space it occupies, which will also lose part of potential customers and interest loss.

3) Graphic preferences

Graphics shall demonstrate information like effect pictures, project name and recent preferential prices. etc.

Advantages: Special offers are always placed in the conspicuous location to attract attention.

Disadvantages: A small amount of information is displayed and customers have to click to view full information to get further information. Or they have to list in search engines to get what they want, and they may find out that the information is not what they want, which cannot quickly provide target information, waste time and let customers being impatient.

4) Soft text preferences

It refers to introduce the progress, special offers, starting price, and sales area in soft texts.

Advantages: The project information is complete and convenient to read.

Disadvantages: A large amount of soft contexts are crowded together and it is hard for customers to find what they want without patience. What's more, it gives a sense of fatigue and it is difficult to arouse interest of reading while comparing to graphics preferences.

5) Real estate recommendation
Real estate of good sales or ideal ones should be reorganized to recommend to customers.

Advantages: Real estate which has problems, such as schedule delay, extension, five cards incomplete, etc won't appear in the recommendation. At least, the recommendations are good choices.

Disadvantages: The price of the recommended ones is relatively high, which is not suitable for those in rigid demand or first home buyers. What's more, the recommended real estate may not meet the demands of territorial complex. Because the quantity is limited, and not all the sections have recommended ones.

\section{B. Promotion through community forum}

Poeple who buy products through Taobao know that they have to read the described information and foucs on other people's comments, which will give relatively accurate comments. What's more, buyers should not only listen to the unilateral statement of sellers because they shall exaggerate the function to achieve attention and get higher profits. And there are similar platforms in the real estate industry, which is community forum.

1) Promotion activities: Crazy corns festival is going to be carried out, which is cheerful

Real estate developers can demonstrate recent promotion activities in owners forum to help more people know and accept this project and even become moved to buy house there.

Owners forum is a good channel for customers who have purchase intention to feel this project, and leave a favorable impression on them to get reputation and fame.

Advantage: Activities which have been promoted can be reviewed in the forum, which can also be posted top with good effects to let potential customers to review these past activities.

Disadvantages: Not every will list in the forum to review and the amount of people involved is small. What's more, people will not purposely go to the scene, they just drop by or go there when they have a holiday and have real purchase intention.

2) Promotions: Buy two-bed room or three-bed room apartment, get travel. Why there is no activities like this when I bought my house?

Real estate developers demonstrate these promotion ways in the forum to let potential customers know and have a desire to buy.

Advantages: Maybe customers have already known this real estate, however there is no big difference from others or each one has its own features, so they don't know how to choose. And if there is such a promotion activities, customers will think they will be given more preference, and the deal will probably not be far off.

Disadvantages: Active members of the forum are prospective owners, and most of the potential customers rarely view the forum, which will not have obvious effect on promotion and lack specificity.

3) Forum decoration: Design competition of SouFan Holdings Ltd Shenyang Station

The website can provide suggestions for the design of forum decoration, and real estate developers can also demonstrate their design. What's more, prospective owners can communicate to know the materials, progress and effect, etc. 
Advantages: Sometimes owners don't have experience about decoration, they don't know how to design and have no knowledge of decoration or ideas about style, which will cause waste of money, ideal effects and extension. However, they can refer to the ideas in the forum and exchange ideas about materials and cost performance, and relevant decoration chores.

Disadvantages: Decoration companies may make soft texts and find some internet mercenaries to create discrepancy in order to misled consumers and cannot make correct judgment. Under this circumstance, both good comments and bad comments cannot be trusted, which may be malicious attacks from competitors.

4) Project schedule: Open day of construction site; House delivery is ready.

Real estate can post information to forum, such as the time to cap, paint facades, carry out internal decoration and community reform, etc. What's more, information also includes the time of pledged chips, opening of sales office, sample room viewing, quotation opening, and new products promoting.

may instantly know the bad news of real estate developers. Inter communication spread fast and information is inadvertently known by everybody. And bad information will cause negative effects on the sales and make sales be in a delimma if it is not properly dealt.

\section{Event marketing}

Event marketing refers to arousing people's interest through discussion on hot topics. There are various hot topics with different communication patterns. For example, hot topics can be further analysis of hot news and network promotion of real estate information and celebrity effect. And approaches include QQ groups. Forum, blog, weibo, wechat, professional website, portal websites, common websites, etc.

\section{1) Popular topics}

Real estate will create popular topics to arouse people's interest at the time of the opening of sales offices, starting of pledged chips, quotation opening and new products promoting.

2) Alternative topics

Alternative topics can be adopted to promote the real estate. For example, you can explain to customers that houses are suitable for the old with good design and property service. What's more there are owners who are peers, as a result they can communicate more, and won't be solitude.

\section{3) Celebrity effect}

Celebrities will attract people. And no matter things happen to them are good or not, which will definitely cause some changes. So celebrity endorsement is a good way of promotion and maybe customers will pay attention to a certain real estate because of the famous person.

\section{4) Online advertising}

There is always a saying that advertisements are banned in TV dramas, and people all have a bad impression on advertisements. So advertisements with creativeness and innovation are in the trend of network promotion. Only by grad people's attention, can it arouse people interest in product information and
Advantages: Prospective owners and house buyers can know all the progresses of the project.

Disadvantages: The progress cannot be completely displayed because news is not updated in time. Sometimes, website will give the information of progress extension, which will affect the sales of real estate and bring bad effects on the project.

Owners interaction: Problems constantly occur before moving in

People know their neighbors when they lived in the old house and even with good relationship. However, they will have a distant relationship with neighbors and contact less with those they want to be close to. However, with the advanced communication, the owners forum is a platform to communicate.

Advantages: Prospective owners can make acquaintance with those who live around through the forum, and some may even live besides you. What's more, they can communicate with the real estate, and know each other and exchange the notifications, which will be convenient.

Disadvantages: All members in the community achieve the goal of marketing promotion. If house buyers have no interest in advertisements, how can they be interested in real estate project.

\section{5) Network promotion through wechat}

Network promotion through wechat refers to promoting based on the platform wechat and enterprises can build up their own public platforms to promote their own real estate.

Features and advantages of wechat marketing: The features and advantages can be accurately conveyed; fully pre-heat; stimulate consumption based on the market; add customers dependence online to direct them to buy in real life; win customers through activities to promote the deal; current affairs, convey brand culture; weather broadcast to give care for customers.

\section{CONCLUSION}

Network is moving into various industries of China, and real estate is no exception. Network is definitely in the trend of times and we cannot change only to face it and embrace challenges.

Mayun's experiences have told us that only when we are ahead of time, can we lead this world. There are problems in real estate network promotion, yet its advantages cannot be neglected with a promising future. So we have to be proficient in the strategies of it

Wechat is now the most popular and common telecommunication facility, and wechat marketing will be or has been the major promotion method. And many real estate projects have adopted the way of wechat marketing, but there are still many problems to be settled.

\section{REFERENCES}

[1] Jiang Likun Practice Bible of Network Marketing, publishing house of electronics industry, 2012.1

[2] Lonliang, Qinli Brief Analysis of the Development Status of Real Estate Network Marketing, expert forum, 13th period in 2011

[3] Gu Xiujun Research on the Current Situation and Development Direction of Real Estate Network Marketing, Enterprise Vitality, 9th period in 2012 
[4] Tang Chunjie Brief Analysis of Real Estate Network Marketing, expert forum, 26th period in 2013

[5] Wu Yuee. Application and Development of Real Estate Network Marketing under Web.2.0, Journal of Hubei University of Economics (Humanities \& Social Science), 11th period in 2010

[6] Cheng Mingshu, Peng Xiaoyu Several Concepts of Real Estate Network Marketing in E-times, China Market, 13th period in 2013

[7] Wangpeng Questions of Real Estate Network Marketing, Fu Jian Computer, 8th period in 2011

[8] Yuan Yuansheng Study of Problems and Countermeasure of Real Estate Network Marketing in China, productivity research, 8th period in 2011

[9] Yangxia, Wang Daijing Brief Analysis of Real Estate Network Marketing, Sci-tech Information Development \& Economy, 5th period in 2014

[10] Qian Pingsheng China's Real Estate Network Marketing, Economic \& Trade Update, 5th volume of November in
2011Zhu Yaqing, Dang Shengli Integrative Research of Real Estate Network Marketing and Traditional Marketing, China Science and Technology Information, 8th period in 2012

[11] Tien Foo Sing.Qi Zhong.Construction and Real Estate NETwork (CORENET), Facilities, 2011 Vol.19 (11)

[12] Xiao-sheng LIU, Zhe DENG, Ting-li WANG.Real estate appraisal system based on GIS and BP neural network.Transactions of Nonferrous Metals Society of China 2011 Vol.21 pp.s626-s630

[13] Louis J Grabowski.Lars Mathiassen.Real estate decision making as actor networks, Journal of Corporate Real Estate, 2013 Vol.15 (2) pp.136-149.

[14] Zhang Shule Practical Network Marketing--- Tactics Analysis of Classic Cases, publishing house of electronics industry, 2010.7

[15] Yu Yuanpeng Advertising Planning and Creation of Real Estate China Architecture \& Building Press, 2012

[16] Yu Yuanpeng Package Promotion Planning of Real Estate, China Architecture \& Building Press, 2012 